Results In the unpaired analyses, an inverse educational gradient in CVD risk was observed, particularly in women. This association was not replicated in the intrapair analyses of female $M Z$ twins, but it persisted among female DZSS twins. For men, the pattern was less clear.

Conclusions The attenuation of association in the intrapair analyses suggest that shared familial factors account for part of the observed association between education and CVD. The fact that it was primarily attenuated in $\mathrm{MZ}$ twins may point to genetic factors as an important source of confounding. However, since education was associated with CVD in the intrapair analysis of DZSS twins, there was still some evidence of effect of education. Finally, these Danish data suggest that the social inequality in CVD is larger for women than for men.

\section{P1-466 EFFECTS OF OUTDOOR TEMPERATURE AND RAIN ON THE RISK OF HEMORRHAGIC STROKE}

doi:10.1136/jech.2011.142976g.55

${ }^{1} \mathrm{R}$ Magalhães, ${ }^{*}$ 1,2 $\mathrm{M}$ Correia, ${ }^{1} \mathrm{M} \mathrm{C}$ Silva. ${ }^{1}$ Instituto Ciências Biomédicas de Abel Salazar, Universidade do Porto, Porto, Portugal, ${ }^{2}$ Centro Hospitalar do Porto, Hospital Santo António, Porto, Portugal

Introduction Changes in meteorological parameters have been associated with stroke occurrence. The incidence of primary intracerebral haemorrhages (PICH) seems to increase in days with cold/ mild outdoor temperature. In Portugal, neurologists forward the hypothesis that the incidence of $\mathrm{PICH}$ increases in rainy days and not particularly low temperatures. This study aims to study the association between occurrence of $\mathrm{PICH}$ and weather parameters.

Methods Data from ACINrpc-project, involving 78 patients suffering a first-ever-in-the-lifetime PICH over a 2-year period in the city of Porto was used. Information on daily weather parameters was obtained from the National Meteorological Office. A Poisson model was used to estimate the association between weather parameters and PICH incidence. Using a conditional logistic regression model, a case-crossover design was then used to estimate the risk of PICH following specific exposures associated with PICH incidence: low diurnal temperature range (DTR) and rainy days. For each subject, the case period was matched with 4 control periods, the same weekday in the previous 4 weeks.

Results PICH incidence increases by $11.8 \%$ (95\% CI 3.8 to $20.4 \%$ ) for $1{ }^{\circ} \mathrm{C}$ drop in DTR and $3.1 \%$ (95\% CI 1.1 to $5.1 \%$ ) for a $1 \mathrm{~mm} / \mathrm{m}^{2}$ in precipitation. Following a day with a $\mathrm{DTR}<4^{\circ} \mathrm{C}$ the $\mathrm{OR}$ is 2.9 (95\% CI 1.4 to 5.8 ), increasing to 8.8 (95\% CI 1.7 to 44.8 ) after a $48 \mathrm{~h}$ exposure. Following days with low DTR and rain, the OR is 3.2 (95\% CI 1.3 to 8.1 ) and 9.5 (95\% CI 1.1 to 88.9$)$ for a precipitation $>10 \mathrm{~mm} / \mathrm{m}^{2}$ and $40 \mathrm{~mm} / \mathrm{m}^{2}$, respectively.

Conclusion Precipitation by itself is not associated with PICH incidence, nevertheless has a synergistic effect in low DTR days.

\section{P1-467 SERO-PREVALENCE OF RIFT VALLEY FEVER IN SOUTHWESTERN SAUDI ARABIA}

doi:10.1136/jech.2011.142976g.56

T Al-Azraqi, A E Mekki, A Mahfouz. ${ }^{*}$ College of Medicine, King Khalid University, Abha, Saudi Arabia

Introduction The objective was to study seroepidemiology and potential risk factors of Rift Valley Fever (RVF) virus infection in South Western Saudi Arabia.

Methods A random sample of the general population were studied. Through questionnaire interviews, data were collected regarding sociodemographic status, housing conditions, animal contact and other relevant information. Blood samples were taken and tested for
RVF-specific IgG and IgM utilising enzyme-linked immunosorbent assays (ELISAs).

Results Out of 2322 persons included in the study, only 139 were positive for RVF-specific IgG giving an overall prevalence of $6.0 \%$. On the other hand, none of the study samples were found to be sero-positive to RVF-specific IgM. The highest prevalence of sero positive RVF IgG was observed in Al Birk of Aseer region (13.3\%) followed by Al-Arda of Jizan Region (11.8\%), where the first animal deaths were reported during 2000-2001 outbreak. The study revealed zero prevalence of specific IgM and IgG among children born after the 2000-2001 outbreak. Using multivariate binary logistic regression analysis, the following significant risk factors were identified; lacking house electricity, having animals in the house, history of slaughtering animals, contact with or transporting aborted animals.

Conclusion The lack of recent virus activity mandates the rigorous maintenance of the control measures undertaken by the Ministries of Agriculture and Health. It is recommended to have regular seroepidemiological surveillance of RVF among humans, fostering public health messages in the region for risk reduction on reducing the risk of animal-to-human transmission as a result of unsafe animal husbandry and slaughtering practices.

\section{P1-468 TOWARDS A MODE OF COLLECTIVE CONSTRUCTION OF EPIDEMIOLOGICAL KNOWLEDGE}

doi:10.1136/jech.2011.142976g.57

${ }^{1} \mathrm{~B}$ Mariana, ${ }^{* 1} \mathrm{M}$ A Lia, ${ }^{1} \mathrm{H}$ Juliana, ${ }^{2} \mathrm{~A}$ M Franci. ${ }^{1}$ Universidad Nacional de Córdoba, Córdoba, Argentina; ${ }^{2}$ Universidad Nacional de Villa María, Córdoba, Argentina

Several Latin-American authors (Breilh, Almeida Filho, Czeresnia, among others) and some Europeans (as Tognoni) argue critically about the ways of constructing knowledge in epidemiology. They coincide in pointing out the limitation of the expert eye to account for the processes collective health. They debate how to manage knowledge and mechanisms to coordinate the management of institutional knowledge to the collective management of knowledge, in order to generate conceptual and methodological tools to impact effectively on the life stage of communities. We hypothesise that comanagement of knowledge, as inter-subjective process between academics and communities, promotes the transforming and democratising actions. In this regard, two national universities in the province of Cordoba, along with a local institution of healthcare built since 2008 an area of informal training, the Permanent Seminar of Epidemiology Community (EC), whose line of work is health as indicator of life, autonomy, knowledge and democracy in the communities. Participants are workers and health promoters from different districts of the province, members of community-based organizations and universities (students and teachers). In this context, it has been done during 2009-2010 a province-wide survey of experiences in community health, encouraging integration of community members to the $\mathrm{EC}$ research network. The progress made in terms of health monitoring and community organising around health is the subject of a manual about EC co-management of knowledge, and realises the real possibilities of achieving them.

\section{P1-469 SOCIOECONOMIC STATUS OF INJURED CHILDREN IN ZANJAN, IRAN}

doi:10.1136/jech.2011.142976g.58

S Mazloomzadeh, ${ }^{*}$ M Hasaniha. Zanjan University of Medical Sciences, Zanjan, Iran

Introduction Injuries are one of public health priorities in Iran Information on injuries in children and its related factors are less well known. The aim of this study was to describe the socioeconomic factors in injured children in Zanjan, Iran. 